\title{
Climate Impacts on the Cost of Solar Energy
}

\section{Abstract}

Photovoltaic (PV) Levelized Cost of Energy (LCOE) estimates are widely utilized by decision makers to predict the long-term cost and benefits of solar PV installations, but fail to consider local climate, which impacts PV panel lifetime and performance. Specific types of solar PV panels are known to respond to climate factors differently. Mono-, poly-, and amorphous-silicon (Si) PV technologies are known to exhibit varying degradation rates and instantaneous power losses as a function of operating temperature, humidity, thermal cycling, and panel soiling. We formulate an extended LCOE calculation, which considers PV module performance and lifespan as a function of local climate. The LCOE is then calculated for crystalline and amorphous Si PV technologies across several climates. Finally, we assess the impact of various policy incentives on reducing the firm's cost of solar deployment when controlling for climate. This assessment is the first to quantify tradeoffs between technologies, geographies, and policies in a unified manner. Results suggest crystalline Si solar panels as the most promising candidate for commercial-scale PV systems due to their low degradation rates compared to amorphous technologies. Across technologies, we note the strong ability of investment subsidies in removing uncertainty and reducing the LCOE, compared to production incentives.

\section{Keywords}

Solar Power, Photovoltaics, Levelized Cost, Climate, Renewable Energy, Silicon PV

\section{JEL codes: Q42, Q43, Q48}




\section{Introduction}

As the global demand for solar power is growing, the development and deployment of solar photovoltaic (PV) technology is also increasing. Installed PV capacity has grown from approximately 14 gigawatts (GW) in 2008 to 180 GW in 2014 worldwide (IHS, 2015), indicating that the combined effects of technological innovation, reduced manufacturing costs, and various governmental programs are allowing the systems to become more economically feasible to install. Deployment of PV systems is poised to help meet the growing global energy demand and reduce the detrimental environmental effects of fossil fuel consumption. Despite incentives, solar electricity generation currently accounts for $7 \mathrm{GW}$, or less than $1 \%$ of U.S. electricity production (EIA, 2015; IHS, 2015). Rapid adoption of a renewable energy technology may be possible when it reaches a critical grid parity, the tipping point at which the lifetime generation cost of a renewable electricity technology is comparable to the price of electricity generated using traditional resources. Levelized cost of electricity (LCOE) is a common metric used to compare energy generation technologies when considering grid parity (Campbell et al., 2008), though other metrics, including job creation and reliability, are often considered (Baer et al., 2015). The debate over the economic feasibility of solar PV technologies in the current electricity marketplace often involves LCOE estimates for PV technology. Recently, LCOE calculations by Deutsche Bank were used to argue solar PV grid parity had already been achieved across 10 states in the U.S. (Shah and Booream-Phelps, 2015). Quantitative comparisons of energy technologies are essential guides in energy policy design. However, the utility of LCOE estimates is limited by both the completeness of lifetime field studies, the inability of LCOE to account for intermittency, and uncertainty in the future cost of electricity. 
Local climate effects on solar PV system lifetime are commonly assumed negligible in the LCOE assessment (Darling et al., 2011). This assumption is in contradiction to numerous studies investigating the impact of temperature and humidity on the panel power production efficiency and panel operational life (Jordan et al., 2012). Variations in local climate conditions are observed to alter the degradation rate of PV devices, and thereby yield significant changes in the total cost of energy produced. Here, we expand the calculation of LCOE for commercialscale solar PV systems (production capacity > 1MW) by incorporating the effects of climate conditions on device lifetime and power output. We compare performance of traditional crystalline silicon and thin-film (amorphous) silicon PV technologies. These technologies are selected based on their prevalence in the market, ease of comparability, and the availability of data from existing field studies for PV performance and degradation rates. ${ }^{1}$ Analysis is conducted based on prevalent climate conditions for Atlanta, GA, Boston, MA, Phoenix, AZ, and Portland, OR. This set of geographical locations allows us to compare PV electricity costs in humid subtropical (Atlanta), humid continental (Boston), desert (Phoenix), and maritime (Portland) climates, to demonstrate the dependence of the LCOE on climate conditions. These areas also correspond to köppen climate zones (see Figure 1) defined on the basis of temperature and moisture and our results are generalizable to other global regions.

$<<<$ insert figure 1 about here $>>>$

We show that degradation rates dramatically impact costs across climates. Additionally, we consider the impacts of existing and proposed investment and production incentive programs

${ }^{1}$ Although PV technology based on cadmium telluride (CdTe) represent a commercially salient technology, limited field studies inhibit inclusion in this analysis. A recent review of PV field degradation rates by Jordan et al (2016) revealed only a handful of field studies on CdTe PVs, with highly variable results. By comparison, the same report identified dozens of studies on each of the included silicon-based technologies. 
Climate Impacts on the Levelized Cost of Solar Energy

for commercial solar PV on lowering the firm's cost of technology deployment in each of the four states. Incentives occurring at the time of installation are most effective at reducing the firm's cost of deploying solar. This analysis concludes with recommendations for policymakers, noting which forms of incentives are most effective at reducing costs, and which climates are best suited for photovoltaic production.

\section{Background}

A LCOE estimate takes into account the total costs and amount of electricity produced over the lifetime of a power plant to determine the overall lifetime cost per kilowatt-hour of electricity produced. Initial capital investments and accruing maintenance costs are discounted over the lifetime of the technology. Solar PV levelized cost calculations are typically performed over a time frame of 20 to 30 years, consistent with most manufacturer's estimates of panel life based on limited data, and assuming a panel has expired once its output reaches $80 \%$ of original production. This is consistent with most warranties, which typically only extend to $80 \%$ of original production (McCabe, 2011). For example, a manufacturer may place a warranty for the first 25 years of the panel life, and replace modules as needed if they sufficiently degrade before that time. Assuming the original firm that manufactured the panels is still in business and honoring their original warranty, manufacturers would be responsible for the cost of panel replacement..Hence, the variability in panel life from region to region may be incurred to the manufacturing firm as an uncertain expense, but is also of importance to the utility, because the panels are only protected from failure over the warranty lifetime and may not be protected at all if the manufacture is no longer in business at the time of failure. In addition, it is in the best interest of the utility to select panels with the lowest relative degradation rate in a given climate, 
Climate Impacts on the Levelized Cost of Solar Energy

as reduced degradation rates may increase panel lifetime well past the manufacture warranty.

With a better understanding of panel degradation rates and subsequent deployment costs, lower prices could be achieved in some regions.

Recent studies have investigated the LCOE of solar PV with a focus on approaching grid parity (Darling et al., 2011; SunPower, 2015). Past estimates are often limited not only by uncertainties in degradation rate and module-level efficiency temperature-response, but also by unclear relationships between these parameters and technology and climate conditions. Though climate-specific factors have traditionally been omitted or assumed to be constant across technologies, some values do appear throughout the literature: Capital costs for each panel type are based on available market data, and we draw on existing LCOE literature to select representative values for operations and maintenance costs, residual values, and discount rates. For climate and climate-impact data, which have no foundation in the LCOE literature, we conduct a meta-analysis of engineering field studies to determine appropriate degradation and efficiency values for each panel type in each climate (see Section 4).

First, annual operations and maintenance costs are nontrivial, contrary to the pervasive tendency to label photovoltaic technology as indefinitely self-sustaining. Much of the cost of solar power is embedded in upfront capital, but to avoid significant efficiency losses from soiling and component failure, regular maintenance is typically required. Maintenance activities include module cleaning, panel wiring, and inverter and grid repairs and can significantly contribute to the operating costs of a commercial PV system. Lawrence Berkeley National Laboratory estimates these “soft costs” of solar between \$20-40/kW annually (Bolinger and Weaver, 2014). We rely on the midpoint of this range for our assessment. 
Climate Impacts on the Levelized Cost of Solar Energy

Second, there are resale markets for used photovoltaic systems (McCabe, 2011). Used modules are sold for off-grid system applications, replacements for broken modules in other systems, or for scrap materials. McCabe (2011) notes that polycrystalline Si (p-Si) cells built with tempered glass may be practical to salvage, but amorphous silicon (a-Si) modules built with breakable float glass may have little value. In either case, markets for used panel modules are not yet mature. Here, we assume no residual value of PV panels past device lifetime.

Third, appropriately selecting the discount rate is important for any long-run investment, particularly solar PV. There is high variability in the discount rates used by the federal government and by companies involved in strategic planning (Arrow et al., 2014). The U.S. Environmental Protection Agency notes that many previous PV investments rely on a discount rate that matched the firm's weighted average cost of capital, were made when interest rates were very high, between 8 and 12\% (U.S. Environmental Protection Agency, 2008). Here, we choose a modest, fixed discount rate of about 3\%, though we assess the LCOE across a range of rates in our sensitivity analysis.

Finally, there is great variety in the types of fiscal and policy measures across the United States. This is in part due to the myriad motivations at play when constructing renewable energy policies. Solar incentives may be initiated to address a variety of market failures and barriers facing renewable technologies. The cost of traditional energy externalizes many negative impacts, reducing competitiveness of renewable resources. Further, high capital costs limit solar technology’s competitiveness. Sunk costs from existing utility infrastructure, regulatory institutional arrangements, and inefficient pricing mechanisms reinforce the status quo. A variety of state-level mandates and regulations incentivizing solar production have been adopted to address imperfect markets. These include renewable portfolio standards, net metering, and 
Climate Impacts on the Levelized Cost of Solar Energy

interconnection standards. However, these regulatory policies do not impact the economic cost of solar (except through the effect of increased supply).

Reaching grid parity may require taxes on polluting energy resources, or incentives for clean energy production (Borenstein, 2012). Solar incentives do not decrease the social cost of PV; rather they redistribute costs to taxpayers. Incentives can reduce the technology deployment cost to the firm. Fiscal assistance from a tax credit or rebate will encourage firms to select a more socially efficient technology.

While the U.S. federal government offers a variety of programs aimed to incentivize the development of renewable energy technologies, state and local governments have innovated numerous policy programs to increase renewable energy capacity and installation (Carley, 2009; Sarzynski et al., 2012). Our analysis addresses how state-level solar PV incentives impact a firm’s cost of producing solar electricity. The subsidies selected for study here include production tax credits (PTC), investment tax credits (ITC), rebates, and grant programs. Production tax credits promote the production of energy by offering some subsidy in dollars per kilowatt-hour produced. Investment tax credits stimulate market entry by offering a subsidy as an estimated percentage of total dollars spent on installing kilowatts of solar power capacity (DSIRE, 2015, 2006). Similarly, rebates or grants are awarded to solar PV installations in dollars per kilowatt-capacity of the systems (Burns and Kang, 2012). The total amount allocated for tax credits, rebate programs, and loans are often limited, in turn limiting the potential impact of these policies.

Note that each of these programs represents a solar subsidy, not a tax directly penalizing externalities of traditional energy production. Though such a Pigouvian tax would be more theoretically efficient, subsidies are the most common incentive in use for solar power in the 
Climate Impacts on the Levelized Cost of Solar Energy

U.S. today. There is some evidence that these programs are quite effective at increasing the deployment of solar PV systems. Sarzynski et al. found that in states where cash incentives such as grants and loans are offered, the installed deployment of PV systems advances much more quickly and comprehensively, compared to other financial incentive programs (2012). Loan programs are often a preferred form of financial incentives for solar PV systems because they can be designed to offer a long timetable to pay back the loan, often at low or no interest, reducing costs to the firm without burdening the taxpayer (Burns and Kang, 2012). However, the loan payback period is often mismatched with the lifetime of the PV system. Panel lifetime has traditionally hindered estimates of the LCOE and the policy effectiveness (Branker et al., 2011; Sarzynski et al., 2012). Grant programs uniquely avoid the payback period, relieving the need to estimate panel lifetime, but quickly exhaust available funds.

The Sarzynski (2012) study is just one piece of evidence that solar incentives reduce firm costs associated with deploying solar PV. The true LCOE is insensitive to the policy arena, meaning the utilities, taxpayers, and ratepayers must pay all costs not assigned to firms through policy measures. It is with this in mind that we develop a LCOE formula capable of precise, local indicators of cost to both the firm (including panel maintenance and replacement costs) and society (including taxpayer subsidies).

\section{Methods}

While most LCOE estimates use generic values for panel life and performance, PV panels degrade at variable rates in different operating conditions and can exhibit lifetimes significantly different from manufacturer estimation (Jordan and Kurtz, 2013). Replacing modules at 80\% efficiency is recommended to allow utilities to phase in new modules, rather than replacing 
Climate Impacts on the Levelized Cost of Solar Energy

entire systems, reducing overall costs and preserving system efficiency (McCabe, 2011).

Therefore, we offer a more precise cost analysis by setting the lifetime $(N)$ of a photovoltaic system as the time it takes for the system to reach $80 \%$ of its starting energy conversion efficiency, expressed as follows:

$$
\left(1-S D R_{i}\right)^{N}=0.8
$$

where $S D R_{i}$ is the system degradation rate for a particular technology under certain climate conditions. System degradation is strongly influenced by technology type, and is primarily driven by temperature, humidity, air quality, and thermal cycling (Jordan et al., 2012).

We assume a standard energy output value $\left(E_{i}\right)$ produced by a solar installation in the initial year of operation and, based on the available solar resource for a particular location, calculate the rated plant capacity required. The rated plant capacity is then used to calculate initial capital installation costs, assuming commercial-scale \$/watt installation costs for both crystalline (about \$3.00/watt) and amorphous (about \$2.70/watt) technologies (Barbose et al., 2014). By using market-based data to determine installed cost on a per watt basis we are able to account for panel efficiency and other factors such as panel weight on the resultant capital cost. The energy produced by an installation in a given location $i$ in year $n$ is given by $E_{\text {in }}$ as follows:

$$
E_{\text {in }}=\left(E_{i} \times \text { coeff } f_{\text {temp }} \times\left[1+\left(T_{i}-T_{\text {std }}\right)\right] \times\left(1-S D R_{i}\right)^{N}\right) / 100 \%
$$

Above, $T$ represents average field operating temperature or temperature at standard operating conditions for location $i$. The term coeff temp is the temperature coefficient of panel efficiency $\left(\% /{ }^{\circ} \mathrm{C}\right)$. Note that temperatures may be interpreted as the module or ambient 
Climate Impacts on the Levelized Cost of Solar Energy

temperature. Module temperatures have been empirically shown to relate to ambient temperature through the following equation (Alonso García and Balenzategui, 2004):

$$
T_{m}=T_{a m b}+E \times(\text { NOCT }-20) / 800
$$

where $T_{m}$ and $T_{a m b}$ are the module and ambient temperatures, respectively. The Nominal Operation Cell Temperature (NOCT) is defined as "the mean solar cell junction temperature within an open-rack module in Standard Reference Environment (SRE),” and is usually included as part of any module data sheet (Alonso García and Balenzategui, 2004, p.1). In Equation 3, E is the total irradiance in $\mathrm{W} / \mathrm{m}^{2}$, and is divided by a factor of 800 , the SRE irradiance. We calculate $T_{m}$ using daily average $T_{a m b}$ in each region and NOCT and $\mathrm{E}$ are held constant at $47^{\circ} \mathrm{C}$ and 1000 $\mathrm{W} / \mathrm{m}^{2}$, respectively. This simplification likely overestimates the average panel operational temperature, but still provides a sound basis for estimating the impact of temperature variation across the climate regions.

The actual amount of electricity generated by a solar system always falls short of the theoretical value due to inherent losses from various sources, including panel soiling, wiring losses, and power conversion losses. These losses may be represented by a derate factor applied to the amount of energy produced. A derate factor of 0.77 is typical (Dobos, 2014). We incorporate the effects of climate impact on PV panel degradation, lifespan, and instantaneous electrical power generation in the LCOE estimate by using in Equations 1-3 directly in the LCOE calculation, expressed as follows: 
Climate Impacts on the Levelized Cost of Solar Energy

$$
L C O E=\frac{\text { capital }-\frac{R V}{(1+D R)^{N}}+\sum_{n=1}^{N} \frac{A O}{(1+D R)^{n}}}{\sum_{n=1}^{N} \frac{E_{\text {in }}}{(1+D R)^{n}}}
$$

The capital costs consist of the upfront costs for panel modules and installation, $A O$ is the annual operations and management costs, and $R V$ is the residual value of the installation after degradation to $80 \%$ efficiency. $D R$ is the discount rate of future payouts, and $S D R$ is the annual system degradation rate. The PV panel operational lifetime $(N)$ is expected to vary by climate region, according to the panel's constant degradation rate. Equation 1 derives $N$ for each technology and climate.

We exclude a variety of social costs and benefits such as averted emissions, green job values, grid reliability, energy payback time, environmental impacts (including silica and heavy metal extraction, panel assembly, and process energy and carbon efficiency), ${ }^{2}$ and other possible qualities of solar that add or detract welfare (Borenstein, 2012), since these are not well known and rarely estimated by policymakers or firms. Still, the calculation has the capacity to take into account relevant financial information and certain policy options (i.e., investment and production tax credits, rebates, depreciation, loan payments, and interest), per Equation 5. An in-depth review of all available policy incentives is beyond the scope of this paper $^{3}$; rather, the aim of this analysis is to assess the impacts of common financial instruments on the cost of solar deployment.

2 The lifecycle impacts of various silicon PV technologies have been studied by several authors. For an exhaustive assessment and comparison between domestic and foreign manufacturer impacts, see Pehnt (2006), Sherwani et al (2010), and Yue et al (2014). The lifecycle assessments are valuable tools for benefit-cost analysis, but a complete review of panel environmental impacts is outside the scope of this analysis.

${ }^{3}$ For a complete review of global solar policies, see Solangi et al. (2011). 
Climate Impacts on the Levelized Cost of Solar Energy

$$
L C O E=\frac{\operatorname{capital}(1-I T C)-\text { rebate }-\sum_{n=1}^{M} \frac{P T C\left(E_{\text {in }}\right)}{(1+D R)^{n}}-\frac{R V}{(1+D R)^{N}}+\sum_{n=1}^{L} \frac{(D E P+I N T) T R+L P}{(1+D R)^{n}}+\sum_{n=1}^{N} \frac{A O(1-T R)}{(1+D R)^{n}}}{\sum_{n=1}^{N} \frac{E_{i n}}{(1+D R)^{n}}}
$$

In this form of the calculation, most of the assumptions from the first part of our analyses apply. Here, however, we account for investment tax credits (ITC), rebates (or grants), and production tax credits (PTC) in proportion to expected degradation over the lifetime or duration of the tax credit $(M)$, and a variety of firm investment accounting measures. These include depreciation (DEP), interest (INT), and loan payments $(L P)$ for the loan payback period, $L$, as well as the company taxes (TR) on a variety of activities. Not every location or project will have each of these incentives and costs, while other projects may incur multiple values for one category. In these cases, values may be entered as zero or summed, respectively.

Equation 5 is consistent with both the equations proposed by (Darling et al., 2011) and SunPower Corporation (2015), but preserves nuance from fiscal, policy, and climate settings. This equation incorporates the impacts of panel degradation, lifespan, initial energy production capacity, investment or production tax credits, and rebates or grants. To the author's knowledge, this is the first time that the tradeoffs between technologies, geographies, and policies have been quantified in a single setting. Note however that this form of the equation does not include policies tangential to solar policy. For example, there is no carbon-offset credit, although in many places where carbon trading or carbon tax schemes exist, the lack of carbon tax on solar generation is an indirect subsidy to renewables.

We assume no difference in the way firms treat tax credits and grants. Though both lower the upfront capital costs, it is possible that discounting occurs over the gap between the investment and the tax credit (which could be more than a year). However, the total difference in perceived value is uncertain. On the other hand, production subsidies are discounted in 
Climate Impacts on the Levelized Cost of Solar Energy

proportion to the year in which that subsidy will occur, since these tax credits reach farther into the future with consistent periodicity.

Our assessment proceeds as follows: first, we conduct a thorough meta-analysis of field studies to determine appropriate parameters for each remaining climate term in our equation. Then, we calculate the LCOE for each region drawing on climate data gathered. We assess the LCOE for both crystalline and amorphous silicon PV technologies with and without policy incentives for each climate specific region.

\section{Data}

In our analysis, we consider the solar irradiance as received by simple flat-plate collectors oriented by latitude, as might be used for a commercial-scale solar PV installation. The irradiance magnitudes for each of our four locations were obtained from the National Renewable Energy Laboratory (Marion and Wilcox, 1994). While many engineering case studies have estimated degradation and panel efficiency under a variety of conditions, these studies vary by technology, climate, and other conditions that limit the generalizability of their results. We conducted an exhaustive meta-analysis of available studies relevant to our selected climates to choose representative values for panel degradation and instantaneous performance efficiency under conditions typical of each location. First we address climate impacts on long-term system viability through degradation, and then we turn to temperature and its impact on instantaneous panel efficiency. Note that, for each case, we assume stable climate conditions throughout the panel lifespan. Though this is a reasonable assumption for short-lived panels, increasing panel longevity (particularly in slow degradation regions) may impact results. Finally, we introduce the policies selected for analysis. 


\subsection{Climate and Panel Degradation}

Solar panels are known to experience irreversible losses in power conversion efficiency due to environmental factors. In particular, high temperature and relative humidity have been shown to correlate with accelerated degradation rates for crystalline (Ross, 2014) and thin film technologies (Albin, 2008). This relationship arises through multiple physical mechanisms. Temperature cycling, for example, results in periodic thermal expansion and contraction of PV materials associated with fatigue failure modes. This is problematic in climates experiencing significant differences between daily temperature extremes, and may be exacerbated by freezing and thawing cycles. Additionally, high temperatures increase the chemical degradation rate for chemical components, according to an Arrhenius relationship, which suggests a doubling of degradation rate for each $10{ }^{\circ} \mathrm{C}$ temperature increase (Ross, 2014). Finally, since waterproof coatings used in solar panel construction do not completely prevent intrusion of water vapor, high humidity environments present a risk of damage due to moisture ingress.

While analytical models for these physical processes have been proposed, even the most rigorous depend on final producer design and manufacturing. To circumvent this issue, and to ensure that our analysis reflects the reality of contemporary solar module production, we select degradation values based on published multi-year field studies of installed solar modules. The median degradation rates reported in various case studies worldwide are highly variable, but it has generally been found that crystalline technologies degrade at a rate of $0.8 \%$ per year and thin film technologies have a degradation rate of approximately 1.5\% per year (Jordan and Kurtz, 2013). In their exhaustive review of PV panel degradation, Jordan and Kurtz also organized panel degradation rates by technology type for a cross-section of climates, reporting similar 
Climate Impacts on the Levelized Cost of Solar Energy

degradation rates for mono-crystalline (m-Si) and poly-crystalline (i.e. multi-crystalline) silicon modules in continental and tropical climates. Numerous other studies have found little difference in degradation rates between the two crystalline silicon technologies, and so we take the mean values provided by Jordan and Kurtz as the expected degradation rates for those both m- and p-Si (2013).

For amorphous silicon technology, where the availability of published degradation rates is sparse by comparison, we must also rely on single-study comparisons across climate regions. One such study, representing five different module manufacturers, provided a proportional comparison among steppe, desert, and maritime climates (Ruther et al., 2008). These proportional variations were normalized to the mean values for amorphous silicon in maritime climates reported in prior works (Jordan and Kurtz, 2013; Ruther et al., 2008). The final degradation values assumed for the analysis section of this study are shown with corresponding expected lifetimes in Figure 2, based on Equation 1. The cities Atlanta, Boston, Phoenix, and Portland represent the humid subtropical, humid continental, midlatitude desert, maritime climates, respectively. These values become inputs to the LCOE. ${ }^{4}$

$<<<$ Insert figure 2 about here $>>>$

Due to a lack of comparable degradation data, the following analysis does not consider aSi technologies in humid continental climate regions (Boston, MA). However, the absence of such data is perhaps attributable to the fact that amorphous silicon was designed for more

${ }^{4}$ Based on limited field studies, it may also be possible to compute the degradation rate, lifespan, and LCOE for CdTe technologies. Degradation rates appear to be modestly higher for cadmium versus crystalline silicon technologies. Thus, the expected panel life would be shorter, leading to a higher long-term cost. However, data are not separable by climate zones relevant to this analysis, so we cannot yet speculate on how CdTe panels would fare in the field in comparison to the Silicon technologies. 
Climate Impacts on the Levelized Cost of Solar Energy

extreme temperatures, and is generally not deployed for such temperate environments.

Qualitatively, the relative advantages for this technology are expected in hotter environments.

The variation in lifetime expectancies underscores the impact of even small differences in annual degradation rate. For m- and p-Si modules, this difference reduces life expectancy in Arizona by over a decade compared to Georgia. At the same time, the desert climate is in fact a relative advantage of for a-Si modules. Notice the comparatively high rate of degradation for aSi in humid climate regions. This is consistent with the expectation that amorphous technologies will be robust in terms of temperature, but sensitive to moisture and frost (Shah et al., 1999).

\subsection{Temperature and Panel Efficiency}

Environmental factors also influence solar LCOE through reversible changes to power conversion efficiency of photovoltaic modules. A manufacturer of a solar panel typically reports an operating temperature coefficient. This is the expected reversible loss in conversion efficiency per unit deviation from normal operating temperature, which we incorporate into our analysis according to Equation 2. Operating temperature of solar modules, furthermore, can be tied to ambient temperature according to Equation 3, and thereby generalized by climate region. In general, an increase in $10^{\circ} \mathrm{C}$ in the crystalline PV panel operating temperature reduces the power

output by roughly 5\%, given all other conditions are held constant (Ponce-Alcántara et al., 2014). However, the power loss in amorphous technologies is about half that of the crystalline materials, and hence amorphous technologies may be favorable in warm climates. For the purpose of our analysis, a survey of reported temperature coefficients and peak efficiencies was conducted across 253 commercially available panels from eight leading manufacturers. A summary of results from this survey is organized in Table 1. 
Climate Impacts on the Levelized Cost of Solar Energy

$<<<$ Insert table 1 about here $>>>$

For currently available modules, mean peak efficiency and power output for a-Si modules is significantly lower than that of crystalline silicon cells, which are comparable to each other. While the close agreement in mean efficiency values between m-Si and p-Si silicon seem to run counter to established advantages of increased crystallinity for solar modules, it may be explained by the substitutive nature of competing solar panel technologies. Newer manufacturing capacity for p-Si panels may be reasonably expected to compete with older production of m-Si panels, and it is possible that a greater number of older m-Si modules offered in secondary markets provide a downward bias for the mean values represented. A thorough substantiation of this possibility is left to future work. Regardless, the values for temperature coefficient, peak power, and peak efficiency are ultimately a reflection of what the market can currently provide.

Collecting useful temperature data presents a greater challenge compared to the irradiance data. While only daylight temperatures impact instantaneous panel performance, longterm degradation is impacted by temperature cycling across the entire panel life. The efficiency of panel performance is dependent on the difference between cell temperature (derived from ambient temperature per Eqn. 3) and standard laboratory conditions. We assume a linear relationship between instantaneous temperature loss due to panel operating temperature and ambient temperature, per Equation 3.

$<<<$ Insert Table 2 about here $>>>$

Ambient temperature data were obtained for each location from hourly normal temperature data from 1981 to 2010 provided by the National Oceanic and Atmospheric Administration (NOAA) National Climatic Data Center (Arguez et al., 2012). Hourly temperatures were sorted assuming a Gaussian distribution of solar energy production vs. 
Climate Impacts on the Levelized Cost of Solar Energy

daytime operating hours. The full width at half maximum (FWHM) of the temperature distribution was calculated within a 9:00AM to 5:00PM timeframe to approximate an average daytime operating temperature. ${ }^{5}$ The final temperature values, including all other LCOE calculation parameters discussed thus far, are summarized in Table 2.

\subsection{Policy Incentives}

In order to assess the impacts of various incentives in use, we select current state-level solar PV incentives from each location. Arizona, Georgia, Massachusetts, and Oregon were chosen to capture regional variation in physical and policy climates. Analysis focuses on incentives promoting commercial-scale projects, at least $1 \mathrm{MW}$ in size, rather than small-scale residential (distributed generation) programs. Note that results may not apply to distributed generation due to increased maintenance costs from panel cleaning across many locations, and to limitations in east-west tracking in small scale installations (this in turn limits the amount of incident solar radiation a panel may convert to electricity).

To streamline analysis, we assess the impact of each policy in isolation, though states sometimes employ multiple incentives. We also elect not to speculate on a particular power provider's line of credit and relationship to its regulators, taxers, and other political players. This simplifies the Equation 5 by dropping fiscal terms unrelated to incentives.

Incentives in our selected states capture much of the variety of possible policy architectures. Arizona, a state known for its copious solar resource, offers a renewable energy production tax credit of $\$ 0.035 / \mathrm{kWh}$ to commercial-scale PV producers. The Arizona Department of Revenue caps this incentive at \$2M annually across producers. The program

\footnotetext{
${ }^{5}$ For a detailed explanation of this calculation, see Markevich and Gertner (1989).
} 
Climate Impacts on the Levelized Cost of Solar Energy

sunsets in 2020 (DSIRE, 2010). In northern Georgia, a state not as well known for renewable energy policies, the Tennessee Valley Authority (TVA) also offers a production incentive in the form of a direct subsidy: the Solar Solution Initiative offers $\$ 0.04 / \mathrm{kWh}$ for ten years to producers in Northeast Georgia. This 10 MW program will be expanded in the year of this writing to 20 MW (TVA, 2012). Hudson Light \& Power (MA), runs the Photovoltaic Incentive Program, which offers a direct rebate of $\$ 1 / \mathrm{W}$ installed, for up to $1,000 \mathrm{~kW}$ of annual installation. Notably, one of the requirements Hudson Light \& Power places on this approval is a 20-year manufacturer warranty (Hudson Light and Power, 2011), which we have shown to be a dubious estimate of panel life, depending on location. Finally, Oregon offers a direct subsidy, similar to Massachusetts, of rebates to power providers through the utilities purchasing the power. The Pacific Gas \& Electric Company offers \$0.72/W for projects over 250kW. Table 3 provides a side-by-side comparison of these policies and their respective geographic contexts.

$<<<$ Insert table 3 about here $>>>$

We first compute the LCOE of solar based only on local climate conditions for a particular state, and then compute the sensitivity of the LCOE to each parameter. We also assess each state's LCOE including values of existing policies. For cross-comparison, we compute the LCOE for each state under a production and an investment incentive. This offers two insights: first, how the LCOE varies across U.S. regions, and second, how effective existing policy mechanisms are at lowering costs to the firm.

\section{Results}

Our first result, the variation in panel life based on degradation rates under differing climate conditions, is initially presented in Figure 2. These are inputs to the calculations summarized in 
Climate Impacts on the Levelized Cost of Solar Energy

Table 4, which shows that panel life has strong implications for the LCOE of solar technologies. The longer a panel endures in a given climate condition, the more electric generation it can produce. Longer lifespans from low degradation rates therefore lower the LCOE. However, instantaneous panel performance also drives the cost of solar. Due to the temperature dependence of instantaneous PV efficiency, additional variation in LCOE is visible across climates and technologies.

$<<<$ Insert table 4 about here $>>>$

$<<<$ Insert figure 3 about here $>>>$

Figure 3 visualizes the dependence of PV LCOE on local climate conditions for different Si technologies. The lowest LCOE for p-Si, a-Si, and m-Si technologies is obtained in regions of high level of solar irradiance. These results confirm the expectations that more PV electricity will be generated in sunny parts of the U.S. (Branker et al., 2011; SunPower, 2015) despite higher operational temperatures and degradation rates.

The results also indicate that m-Si are p-Si are more monetarily attractive across all climate regions and are statistically indistinguishable using the current methods. Arizona is the only state in which a-Si is more cost effective than the crystalline technologies, though the difference is not statistically significant in this hot and dry climate. The LCOE was not significantly different for $\mathrm{p}-\mathrm{Si}$ and $\mathrm{m}-\mathrm{Si}$ in any of the climate regions due to similar degradation rates and temperature coefficients. Furthermore, the installation cost per watt of capacity was assumed to be the same for the two types of crystalline technologies, contributing to their nearly identical LCOE values. For the remainder of this paper, we will focus on the difference of crystalline and amorphous technologies. 
Climate Impacts on the Levelized Cost of Solar Energy

Some of the difference in LCOE estimates can be explained by different parameter selections. Though we rigorously reviewed available estimates for each value in the LCOE formula, we acknowledge that even a small change in some of these values may aggregate to a large difference in the final LCOE. To get a better sense of how uncertainty of a parameter could impact cost estimates, we run a sensitivity analysis for each variable in Equation 4, including the energy term in the expanded form.

To perform our sensitivity analysis, a baseline case for each state and panel type is considered based on empirical findings in the literature. These initial parameters are summarized in Table 2. Once the base conditions are known, each variable is perturbed ceteris paribus by $10 \%$ of its initial value, and the resulting LCOE solution is compared to the baseline values. $<<<$ Insert figure 4 about here $>>>$

Figure 4 confirms that the LCOE across all technologies and regions is very sensitive to the available solar radiation. It also demonstrates the LCOE is dependent on the capital costs of each of the panel types. Some parameters have large potential impacts on the LCOE across the technologies and regions, but others have highly variable impacts: system degradation rates and discount rates may contribute to large changes in the LCOE, depending on the region. This is because these terms compound over the course of years. The panel losses due to instantaneous temperature differences have little effect on the LCOE. Relative to other parameters such as system degradation rate, these variables do not have a large effect on the total energy produced from the panels annually.

Note that Figure 4 describes sensitivity, while Figure 3 includes descriptions of uncertainty. These measures are distinguished methodologically: sensitivity is the result of a theoretical change in one variable at a time, while uncertainty is based on the accuracy with 
Climate Impacts on the Levelized Cost of Solar Energy

which each parameter is actually known. In calculating the LCOE, some parameters are selected based on best estimates (i.e. discount rates), for which sensitivity is a useful measure. Other parameters are average values based on empirically gathered data. Statistical deviations from these empirical means are then taken into account as upper and lower bounds using a 95\% confidence interval. These bounds make up the uncertainty in our model and are what contribute to error bars seen in Figure 3.

$<<<$ Insert table 5 about here $>>>$

Table 5 lists the state-specific LCOE when accounting for solar incentives per Equation 5, alongside the associated percent reduction in LCOE. Recall that no information about the longevity of a-Si technologies in cool and humid climates is available, limiting our analysis for the impact of policies on that technology for Massachusetts.

$<<<$ Insert figure 5 about here $>>>$

Finally, we assess a general form of the PTC and investment rebate across all four regions. From Figure 5, we observe that the most effective policy to reduce LCOE in all regions and across all technologies would be a $\$ 1 /$ watt rebate or grant, assuming the same amount of panels are subsidized under any policy scheme.

\section{Discussion}

A thorough analysis of competitiveness of solar PV, considering both climate region and technology type, is essential for the proper design of renewable energy policies in the United States and globally. We have demonstrated the impact of local climate effects on solar PV system performance on the LCOE of electricity from solar PV technologies. In this, we have considered the degradation of Si-based PV technologies in four U.S. states and their representative climate, and contextualized the resulting differences in LCOE within existing 
Climate Impacts on the Levelized Cost of Solar Energy

policy incentives for solar power within those states. Our findings demonstrate substantial variation in panel lifetimes across technologies, which can be well in excess of standard lifetimes guaranteed by manufacturers. The LCOE calculations presented here, considering climatedependent degradation, suggest monocrystalline Si solar panels as the most promising candidate for commercial-scale PV systems despite higher upfront costs and temperature coefficients. As seen in Table 4, the LCOE using monocrystalline Si panels ranges from $\$ 0.138 / \mathrm{kWh}$ to $\$ 0.172 / \mathrm{kWh}$ across the four climate regions, with the lifetime expectancy of the systems ranging between 21 to 40 years. This suggests that novel PV technologies developed to mitigate the loss of efficiency at high temperatures, including a-Si, may only be worthwhile after panel degradation is limited.

We can compare our LCOE predictions with the EIA estimate for the levelized cost of solar energy. The EIA considers a fixed cost recovery lifetime of 30 years, which is higher than most of our expected panel lifetimes, based on empirical degradation rates. The EIA also does not specify the specific panel types considered or the impacts of climate on panel performance. However, they forecast that the levelized cost of new solar photovoltaic power will be \$0.130/kWh (in 2012 dollars) after 2019 (Annual Energy Outlook, 2014). Overall, our LCOE predictions have a similar magnitude to the generalized EIA LCOE forecast, while reflecting the large variability of LCOE with technology type and geographic region. To our knowledge, we are the first to quantify the relationships between efficiency, degradation, and climate in terms of overall costs.

The climate-sensitivity of solar PV LCOE has many additional policy implications. Further analysis can be performed to identify the optimal policy mechanisms for deploying solar across technological and geographic differences. Here, the reduction in LCOE as a result of 
Climate Impacts on the Levelized Cost of Solar Energy

policy is an indicator of the increased competitiveness for different solar PV technologies. Our findings, indicated in Table 5, suggest that policy incentives produce the greatest impact on a-Si PV systems, decreasing the LCOE by 12.8 to 24.7 per cent across the climate regions (excluding Massachusetts). We attribute this result to the fact that a-Si PV panels exhibit the shortest estimated production lifetimes and the highest lifetime costs for commercial-scale systems. Subsidies cause larger relative changes in a-Si LCOE because the initial costs are distributed over a shorter production lifetime.

We consistently find that the investment incentives provide the greatest reduction in LCOE, followed by production incentives, as seen in Figure 5. This is partially explained by the duration of the policy incentives: rebates and subsidies help with upfront costs, whereas production-based policies play out over the long-run. Future payouts are discounted, and due to the uncertainty of panel life, may not be as useful to the firm as grant or rebate money.

Investment subsidies are most effective at lowering the LCOE, but are not necessarily the most theoretically efficient at encouraging renewable energy production. That is, by subsidizing investment, rather than production, policymakers only indirectly encourage the market behavior they seek. Investment tax credits overcome capital barriers to deployment, which appears in this analysis to be the largest barrier to clean energy adoption. On the other hand, production subsidies stimulate renewable electricity generation, rather than reliance on fossil fuels. Though production incentives are more consistent with the desired behavior, without the investment subsidy, generators with high and new capital costs will be less able to compete with traditional and existing sources of power. The subsidy per unit of capacity installed reduces the risks of PV, but does not guarantee that firms actually produce long-term. 
Climate Impacts on the Levelized Cost of Solar Energy

Despite the demonstrated advantage of rebates, grants, and ITCs, many policy programs favor PTCs. However, our results demonstrate that even a modest PTC can lower the LCOE in a way that lowers the cost of solar investments. Though these results speak to the capability of both incentive structures, they do not directly indicate the cost-effectiveness of each policy program. A trade-off exists between the present amount of available funds for effective investment subsidies and the long-term need for public funding for more efficient production subsidies. Investment incentives appear more effective at lowering the cost of solar while funding the activity only once, rather than relying on uncertain future funds. Future work may allow the analyst to optimize available incentive funding with respect to time. An example of this can be seen in Figure 5: the subsidized LCOE for Georgia is lower as a result of its rebate program than it would be under some PTC, regardless of the technology of choice. This result is key to answering a critical policy debate over where and how solar incentives should be applied.

\section{Conclusions and Policy Implications}

Although solar electricity generation is not at present a major global electricity resource, improvements in PV device lifetimes and policy program designs are poised to advance the competitiveness of solar power as a viable source of electricity in the United States and throughout the world. Our LCOE formula can be applied to a host of policy scenarios, including the commercial-scale incentives we assess in this paper, as well as utility- and residential-scales, or distributed generation, at which installation and maintenance costs vary. Direct comparisons of the cost-effectiveness of policies may be executed, in terms of total public expenditure per unit LCOE reduction. An analysis of rate cases and power purchase agreements may reveal the extent to which utilities are currently under- or overpricing their regional PV production. 
Climate Impacts on the Levelized Cost of Solar Energy

Internationally, this technique has the potential to inform climate policy, as nations seek to reduce pollution emissions at least cost. The climate-sensitive LCOE may reveal regions in which particular technologies are more cost-effective, or regions in which the deployment of solar PV panels will be cheaper overall. This may become an important component for determining how funding sources like the Green Climate Fund may be distributed, or which Joint Implementation projects will be deemed acceptable under the Clean Development Mechanism. As the national and international grid becomes increasingly reliant on distributed and renewable resources, this metric must be continue to be refined, making the LCOE more representative of actual costs and benefits associated with one of the world's most promising energy resources. Moreover, as climate change begins to more noticeably shift regional patterns of temperature, humidity, and precipitation, decision makers will require a more intimate understanding of how panels perform and degrade under changing conditions. Hotter temperatures and increased humidity in many regions of the globe will shift technology preferences towardstechnologies that are stable in these conditions.

Though not a complete policy analysis toolbox on its own, the LCOE presented here can be combined with other indicators including job creation or other externalities to more fully compare the total impacts, costs, and benefits associated with solar PV.

\section{Acknowledgements}

The National Science Foundation, grant \#1069138, supported this research. We would like to thank Daniel A. Gordon for his insights, and Doctors Emanuele Massetti, Valerie Thomas, Juan Moreno-Cruz, Marilyn Brown, and the entire Climate and Energy Policy Laboratory for their helpful comments and criticisms. All errors are the authors own. 
Climate Impacts on the Levelized Cost of Solar Energy

\section{References}

Albin, D.S., 2008. Accelerated stress testing and diagnostic analysis of degradation in CdTe solar cells, in: Dhere, N.G. (Ed.), SPIE 7048, Reliability of Photovoltaic Cells, Modules, Components, and Systems, 70480N. San Diego, CA. doi:10.1117/12.795360

Alonso García, M.C., Balenzategui, J.L., 2004. Estimation of photovoltaic module yearly temperature and performance based on Nominal Operation Cell Temperature calculations. Renew. Energy 29, 1997-2010. doi:10.1016/j.renene.2004.03.010

Annual Energy Outlook, 2014. Levelized Cost and Levelized Avoided Cost of New Generation Resources in the Annual Energy Outlook 2014.

Arguez, A., Durre, I., Applequist, S., Vose, R.S., Squires, M.F., Yin, X., Heim, R.R., Owen, T.W., 2012. NOAA’s 1981-2010 U.S. Climate Normals: An Overview. Bull. Am. Meteorol. Soc. 93, 1687-1697. doi:10.1175/BAMS-D-11-00197.1

Arrow, K.J., Cropper, M.L., Gollier, C., Groom, B., Heal, G.M., Newell, R.G., Nordhaus, W.D., Pindyck, R.S., Pizer, W. a., Portney, P.R., Sterner, T., Tol, R.S.J., Weitzman, M.L., 2014. Should Governments Use a Declining Discount Rate in Project Analysis? Rev. Environ. Econ. Policy 8, 145-163. doi:10.1093/reep/reu008

Baer, P., Brown, M. a., Kim, G., 2015. The job generation impacts of expanding industrial cogeneration. Ecol. Econ. 110, 141-153. doi:10.1016/j.ecolecon.2014.12.007 
Climate Impacts on the Levelized Cost of Solar Energy

Barbose, G., Weaver, S., Darghouth, N., 2014. Tracking the Sun VII: An Historical Summary of the Installed Price In the United States from 1998 to 2013. Berkeley.

Bolinger, M., Weaver, S., 2014. Utility-Scale Solar 2013: An Empirical Analysis of Project Cost, Performance, and Pricing Trends in the United States. Berkeley, CA.

Borenstein, S., 2012. The Private and Public Economics of Renewable Electricity Generation. J. Econ. Perspect. 26, 67-92.

Branker, K., Pathak, M.J.M., Pearce, J.M., 2011. A review of solar photovoltaic levelized cost of electricity. Renew. Sustain. Energy Rev. 15, 4470-4482. doi:10.1016/j.rser.2011.07.104

Burns, J.E., Kang, J.-S., 2012. Comparative economic analysis of supporting policies for residential solar PV in the United States: Solar Renewable Energy Credit (SREC) potential. Energy Policy 44, 217-225. doi:10.1016/j.enpol.2012.01.045

Campbell, M., Aschenbrenner, P., Blunden, J., Smeloff, E., Wright, S., 2008. The drivers of the levelized cost of electricity for utility-scale photovoltaics.

Carley, S., 2009. State renewable energy electricity policies: An empirical evaluation of effectiveness. Energy Policy 37, 3071-3081. doi:10.1016/j.enpol.2009.03.062

Darling, S.B., You, F., Veselka, T., Velosa, A., 2011. Assumptions and the levelized cost of energy for photovoltaics. Energy Environ. Sci. 4, 3133. doi:10.1039/c0ee00698j

Dobos, A.P., 2014. PVWatts Version 5 Manual PVWatts Version 5 Manual. Golden, CO. 
Climate Impacts on the Levelized Cost of Solar Energy

DSIRE, 2015. NC Tax Credit Guidelines [WWW Document]. Renew. Energy Tax Credit. URL http://programs.dsireusa.org/system/program/detail/540

DSIRE, 2010. Arizona Senate Bill 1254 of 2010 [WWW Document]. Renew. Energy Prod. Tax Credit. URL http://programs.dsireusa.org/system/program/detail/4159

DSIRE, 2006. R.R.S. Neb. Â§ 77-27, 235 [WWW Document]. Renew. Energy Tax Credit. URL http://programs.dsireusa.org/system/program/detail/1837

EIA, 2015. Monthly Energy Review [WWW Document]. Total Energy. URL http://www.eia.gov/totalenergy/data/monthly/previous.cfm

Hudson Light and Power, 2011. PHOTOVOLTAIC INCENTIVE PROGRAM (MASSACHUSETTS) [WWW Document]. Energy.gov. URL http://www.energy.gov/savings/hudson-light-and-power-photovoltaic-incentive-programmassachusetts

IHS, 2015. Top Solar Power Industry Trends for 2015.

Jordan, D.C., Kurtz, S.R., 2013. Photovoltaic Degradation Rates — an Analytical Review. Prog. PHOTOVOLTAICS Res. Appl. 21, 12-29. doi:10.1002/pip

Jordan, D.C., Kurtz, S.R., VanSant, K., Newmiller, J., 2016. Compendium of Photovoltaic Degradation Rates. Progress in Photovoltaics: Research and Applications. 7 February 2016. doi:10.1002/pip.2744. 
Climate Impacts on the Levelized Cost of Solar Energy

Jordan, D.C., Wohlgemuth, J.H., Kurtz, S.R., 2012. Technology and Climate Trends in PV Module Degradation, in: Proceedings of the 27th European Photovoltaic Solar Energy Conference. Golden, CO.

Marion, W., Wilcox, S., 1994. The Solar Radiation Data Manual for Flat-Plate and Concentrating Collectors. Golden, CO. doi:10.2172/10169141.

Markevich, N., Gertner., I., 1989. Comparison among methods for calculating FWHM. Nucl. Instruments Methods Phys. Res. Sect. A Accel. Spectrometers, Detect. Assoc. Equip. 283, 72-77.

McCabe, J., 2011. SALVAGE VALUE OF PHOTOVOLTAIC SYSTEMS, in: World Renewable Energy Forum. Littleton, CO.

Mitchell, S.M. and D., 2012. Compare Solar Panels [WWW Document]. URL http://www.solardesigntool.com/compare-solar-panels-modules.html

Ponce-Alcántara, S., Connolly, J.P., Sánchez, G., Míguez, J.M., Hoffmann, V., Ordás, R., 2014. A Statistical Analysis of the Temperature Coefficients of Industrial Silicon Solar Cells. Energy Procedia 55, 578-588. doi:10.1016/j.egypro.2014.08.029

Ross, R.G., 2014. PV Reliability Development Lessons From JPL’ s Flat Plate Solar Array Project 4, 291-298.

Ruther, R., del Cueto, J., Tamizh-Mani, G., Montenegro, a. a., Rummel, S., Anderberg, a., von Roedern, B., 2008. Performance test of amorphous silicon modules in different climates - 
Climate Impacts on the Levelized Cost of Solar Energy

year four: Progress in understanding exposure history stabilization effects. 2008 33rd IEEE Photovolatic Spec. Conf. 1-5. doi:10.1109/PVSC.2008.4922773

Sarzynski, A., Larrieu, J., Shrimali, G., 2012. The impact of state financial incentives on market deployment of solar technology. Energy Policy 46, 550-557. doi:10.1016/j.enpol.2012.04.032

Shah, A., Torres, P., Tscharner, R., Wyrsch, N., Keppner, H., 1999. Photovoltaic Technology: The Case for Thin-Film Solar Cells. Science (80-. ). 285, 692-698. doi:10.1126/science.285.5428.692

Shah, V., Booream-Phelps, J., 2015. F.I.T.T. for investors: Crossing the Chasm. New York.

Solangi, K.H., Islam, M.R., Saidur, R., Rahim, N. a., Fayaz, H., 2011. A review on global solar energy policy. Renew. Sustain. Energy Rev. 15, 2149-2163. doi:10.1016/j.rser.2011.01.007

SolarWorld AG, 2015. Technical Downloads [WWW Document]. SolarWorld USA. URL http://www.solarworld-usa.com/technical-downloads/datasheets

SunPower, 2015. SunPower Solar Resource Center [WWW Document]. U.S. SunPower. URL http://us.sunpower.com/solar-resources/

TVA, 2012. Solar Solutions Initiative [WWW Document]. Renew. Stand. Offer. URL http://www.tva.com/renewablestandardoffer/ssi.htm

U.S. Environmental Protection Agency, 2008. Understanding Cost-Effectiveness of Energy Efficiency Programs: Best Practices, Technical Methods, and Emerging. Washington D.C. 
Climate Impacts on the Levelized Cost of Solar Energy

Yingli Solar, 2015. Products [WWW Document]. Yingli Sol. URL

http://www.yinglisolar.com/us/products/solar-modules/ 


\section{Figures:}

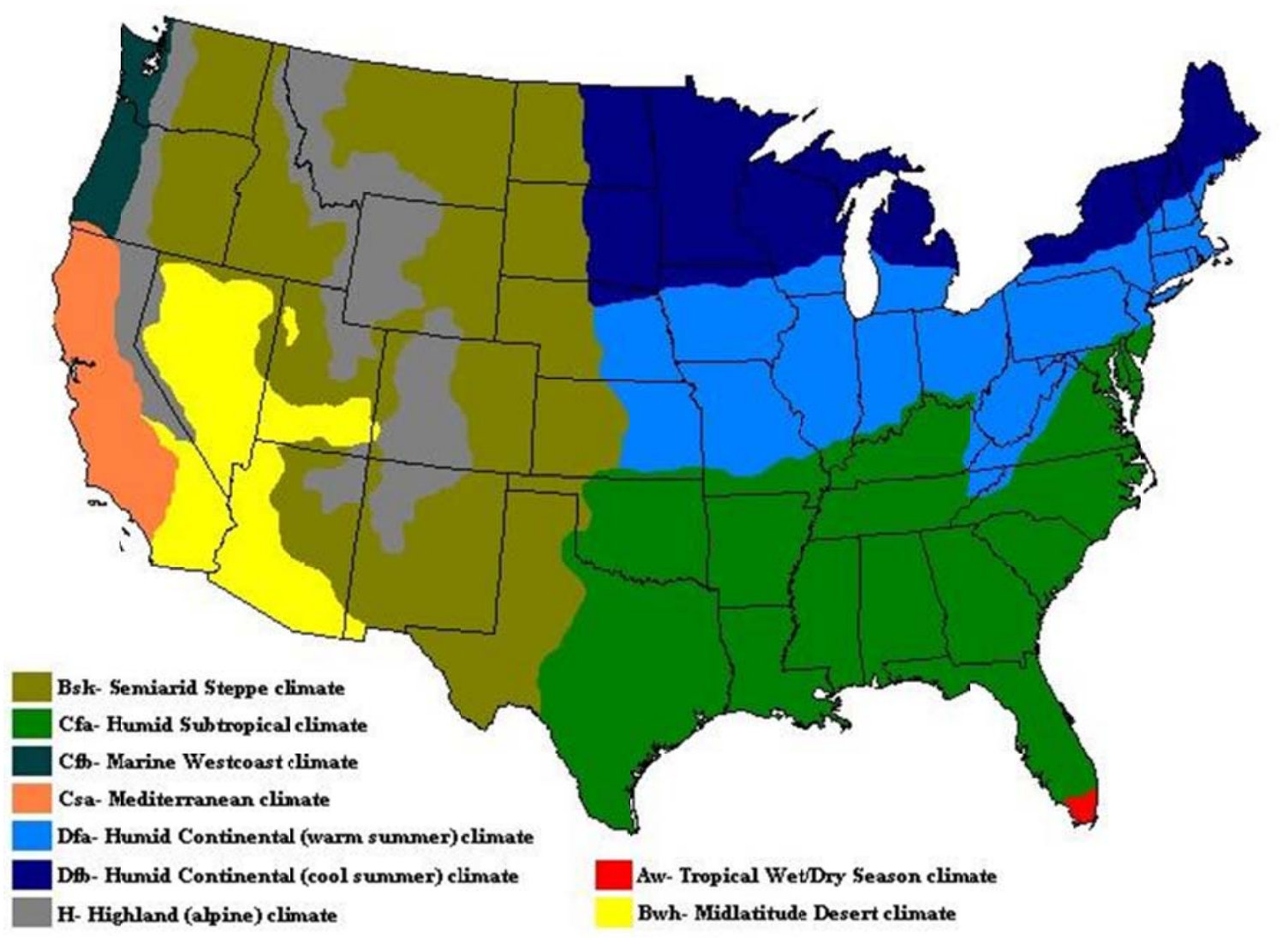

Figure 1: Climate zones for the United States. Available from: http://upload. wikimedia.org/ wikipedia/commons/5/57/Climatemapusa2.PNG. 
Climate Impacts on the Levelized Cost of Solar Energy

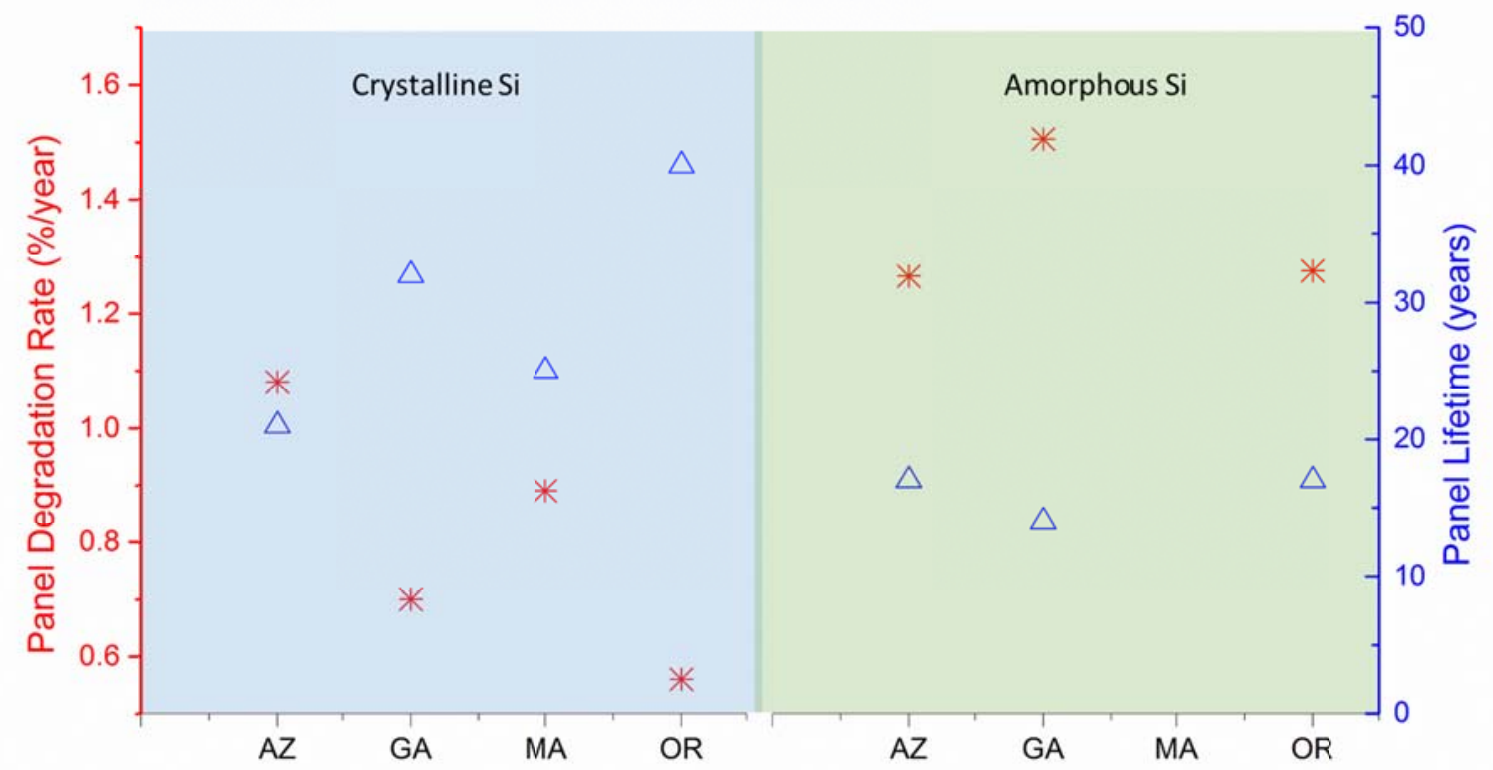

Figure 2: Degradation rates determined from studies of crystalline (Jordan et al., 2012) and amorphous silicon (Ruther et al., 2008) solar modules for several climate regions. Values for amorphous silicon in desert regions is normalized to an adequately large data set. (Jordan and Kurtz, 2013) and panel life expectancy is computed from degradation rates according to Equation 1. 
Climate Impacts on the Levelized Cost of Solar Energy

Table 1: Performance parameters of silicon-based solar technologies across eight leading manufacturers (Mitchell, 2012; SolarWorld AG, 2015; SunPower, 2015; Yingli Solar, 2015). Mean values were computed with equal weight given to each company with respect to performance of each module type.

\begin{tabular}{cccccccccccc}
\hline Module & \multicolumn{2}{c}{ Temp. Coefficient $\left(\% /{ }^{\circ} \mathbf{C}\right)$} & \multicolumn{2}{c}{ Peak Power $\left(\mathbf{W} / \mathbf{f t}^{2}\right)$} & \multicolumn{2}{c}{ Peak Efficiency (\%) } \\
Type & Mean & Min & Max & Mean & Min & Max & Mean & Min & Max \\
\hline mono-Si & 0.44 & 0.30 & 0.48 & 14.23 & 11.60 & 19.66 & 15.34 & 12.50 & 21.50 \\
multi-Si & 0.45 & 0.40 & 0.49 & 13.35 & 11.30 & 14.80 & 14.34 & 12.15 & 16.00 \\
a-Si & 0.28 & 0.20 & 0.39 & 7.90 & 5.50 & 10.60 & 8.50 & 5.87 & 11.39 \\
\hline
\end{tabular}


Climate Impacts on the Levelized Cost of Solar Energy

Table 2: Parameters used for baseline case in sensitivity analysis.

\begin{tabular}{|c|c|c|c|c|c|c|c|c|c|c|c|c|c|}
\hline \multirow[b]{2}{*}{ Parameters } & \multirow[b]{2}{*}{ Units } & \multicolumn{4}{|c|}{ Monocrystalline Silicon } & \multicolumn{4}{|c|}{ Polycrystalline Silicon } & \multicolumn{4}{|c|}{ Amorphous Silicon (Thin Film) } \\
\hline & & $\mathbf{A Z}$ & GA & MA & OR & $\mathbf{A Z}$ & GA & MA & OR & $\mathbf{A Z}$ & GA & MA & OR \\
\hline Irradiance & $\mathrm{kWh} / \mathrm{m}^{2}-\mathrm{yr}$ & 2372.5 & 1855.9 & 1662.2 & 1423.5 & 2372.5 & 1855.9 & 1662.2 & 1423.5 & 1423.5 & 2372.5 & 1855.9 & 662.2 \\
\hline Panel Power / Area & $\mathrm{kW} / \mathrm{m}^{2}$ & 135 & 135 & 135 & 135 & 110 & 110 & 110 & 110 & 54 & 54 & 54 & 54 \\
\hline Efficiency & $\%$ & 15.47 & 15.47 & 15.47 & 15.47 & 14.171 & 14.171 & 14.171 & 14.17 & 8.497 & 8.497 & 8.497 & 8.497 \\
\hline Capital Costs & $\$ / \mathrm{kW}$ & 3000 & 3000 & 3000 & 3000 & 3000 & 3000 & 3000 & 3000 & 2700 & 2700 & 2700 & 2700 \\
\hline Annual Operations & $\$ / \mathrm{kW}$ & 30 & 30 & 30 & 30 & 30 & 30 & 30 & 30 & 30 & 30 & 30 & 30 \\
\hline Degradation Rate & $\%$ & 1.08 & 0.7 & 0.89 & 0.56 & 1.08 & 0.7 & 0.89 & 0.56 & 1.34 & 1.33 & - & 1.59 \\
\hline Discount Rate & $\%$ & 2.87 & 2.87 & 2.87 & 2.87 & 2.87 & 2.87 & 2.87 & 2.87 & 2.87 & 2.87 & 2.87 & 2.87 \\
\hline Temp. Difference & ${ }^{\circ} \mathrm{C}$ & 32.75 & 24.75 & 19.75 & 21.75 & 32.75 & 24.75 & 19.75 & 21.75 & 21.75 & 32.75 & 24.75 & 19.75 \\
\hline Temp. Coefficient & $\% /{ }^{\circ} \mathrm{C}$ & 0.454 & 0.454 & 0.454 & 0.454 & 0.444 & 0.444 & 0.444 & 0.444 & 0.281 & 0.281 & 0.281 & 0.281 \\
\hline
\end{tabular}


Climate Impacts on the Levelized Cost of Solar Energy

Table 3: PV policy incentives listed by state, policy type, duration, and incentive amount.

\begin{tabular}{llll} 
State & \multicolumn{1}{c}{ Policy } & Policy Duration & Incentive \\
\hline AZ & Production Tax Credit (PTC) & 5 years & $\$ 0.35 / \mathrm{kWh}$ \\
GA & Production Subsidy & 10 years & $\$ 0.04 / \mathrm{kWh}$ \\
MA & Rebate on Investment & n/a & $\$ 1.00 / \mathrm{W}$ \\
OR & Rebate on Investment & n/a & $\$ 0.72 / \mathrm{W}$ \\
\hline
\end{tabular}

Table 4: Panel life and LCOE listed by technology and climate zone.

\begin{tabular}{|c|c|c|c|}
\hline Location & Climate Zone & $\begin{array}{l}\text { Crystalline LCOE } \\
\text { (life span in years) }\end{array}$ & $\begin{array}{l}\text { Amorphous LCOE } \\
\text { (life span in years) }\end{array}$ \\
\hline $\mathbf{A Z}$ & Midlatititude Desert & $\$ 0.143(21)$ & $\$ 0.141(17)$ \\
\hline GA & Humid Subtropical & $\$ 0.138$ (32) & $\$ 0.201$ (14) \\
\hline MA & Humid Continental & $\$ 0.172(25)$ & -- \\
\hline OR & Maritime & $\$ 0.159(40)$ & $\$ 0.227$ (17) \\
\hline
\end{tabular}


Climate Impacts on the Levelized Cost of Solar Energy

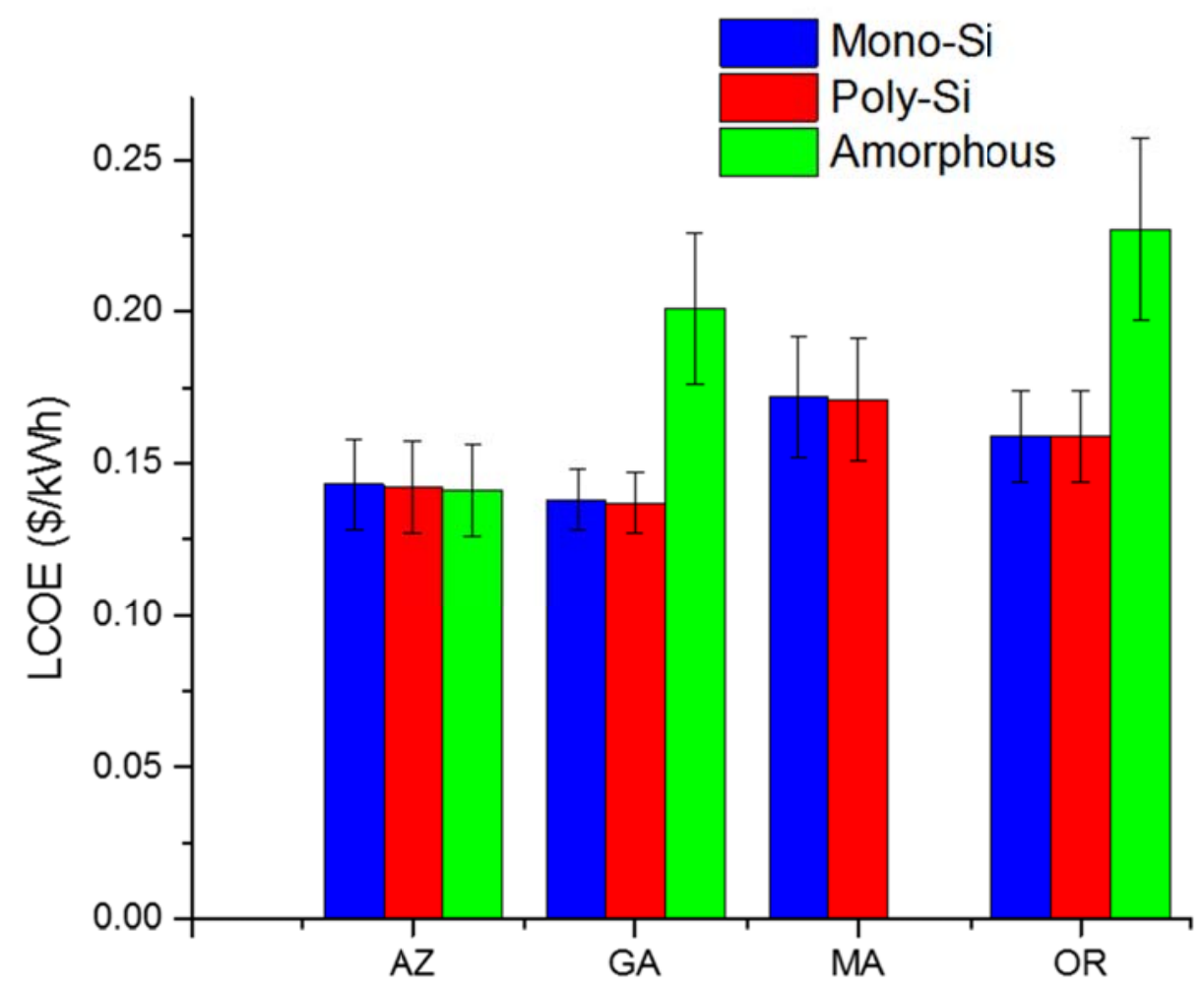

Figure 3: LCOE calculated for polycrystalline (p-Si), amorphous (a-Si), and monocrystalline (m-Si) silicon solar PV technologies in the four climate conditions. Error bars indicate 95\% confidence intervals. 


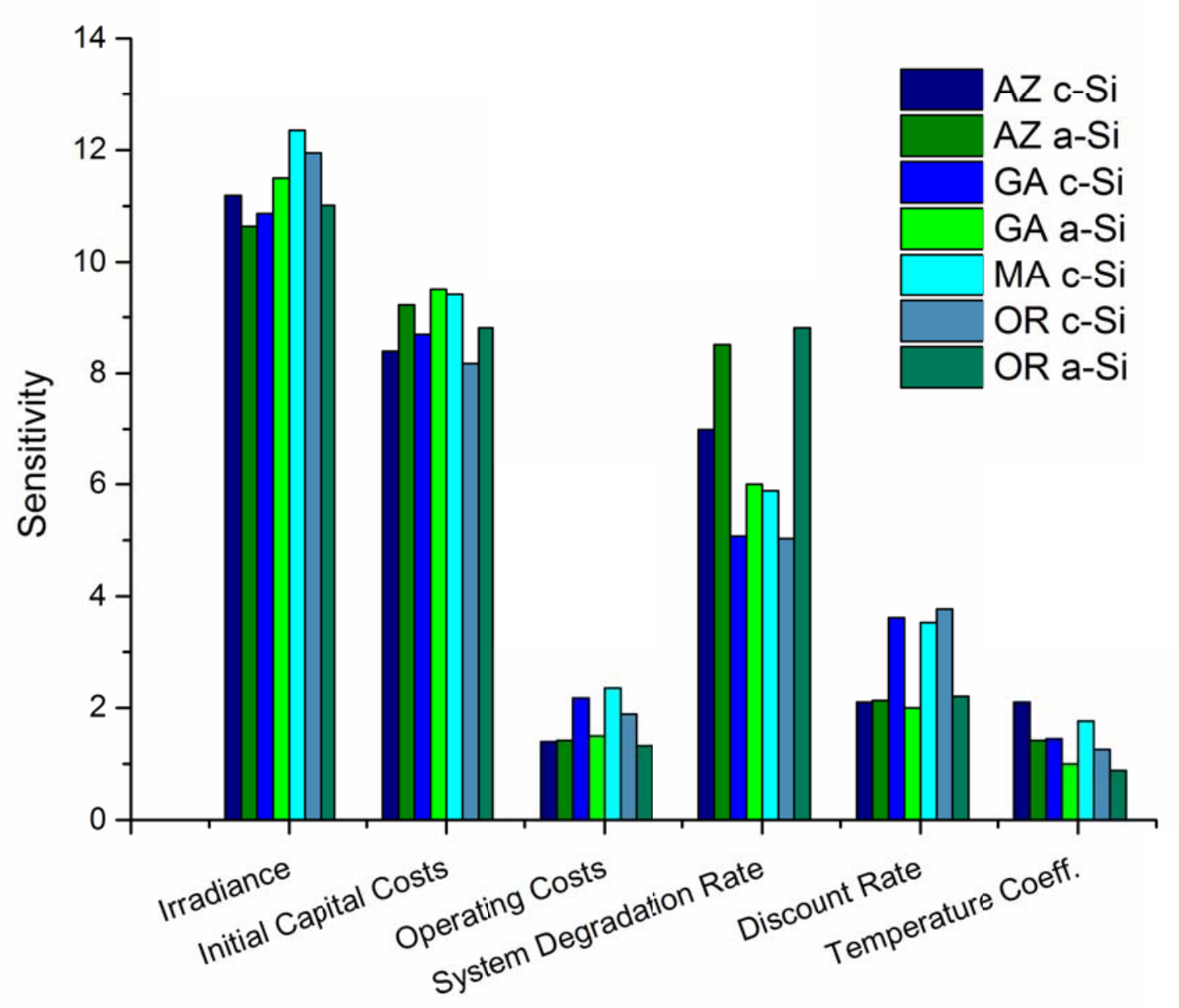

Figure 4: Sensitivity analysis of LCOE from Equation 4, using mean values for each location and technology for the baseline consideration and perturbing each variable by $10 \%$ in order to investigate its sensitivity to the model. 
Climate Impacts on the Levelized Cost of Solar Energy

Table 5: Impact of existing policies on LCOE listed by state and technology.

\begin{tabular}{clcc}
\hline Location (Climate) & \multicolumn{1}{c}{ Policy Type } & $\begin{array}{c}\text { Crystalline LCOE } \\
\text { (\%Reduction) }\end{array}$ & $\begin{array}{c}\text { Amorphous LCOE } \\
\text { (\%Reduction) }\end{array}$ \\
\hline AZ (Desert) & PTC & $\$ 0.133(6.99)$ & $\$ 0.123(12.77)$ \\
GA (Subtropical) & Production Subsidy & $\$ 0.121(12.3)$ & $\$ 0.171(14.93)$ \\
MA (Continental) & Rebate on Investment & $\$ 0.123(28.49)$ & - \\
& & & $\$ 0.171(24.70)$ \\
\hline
\end{tabular}

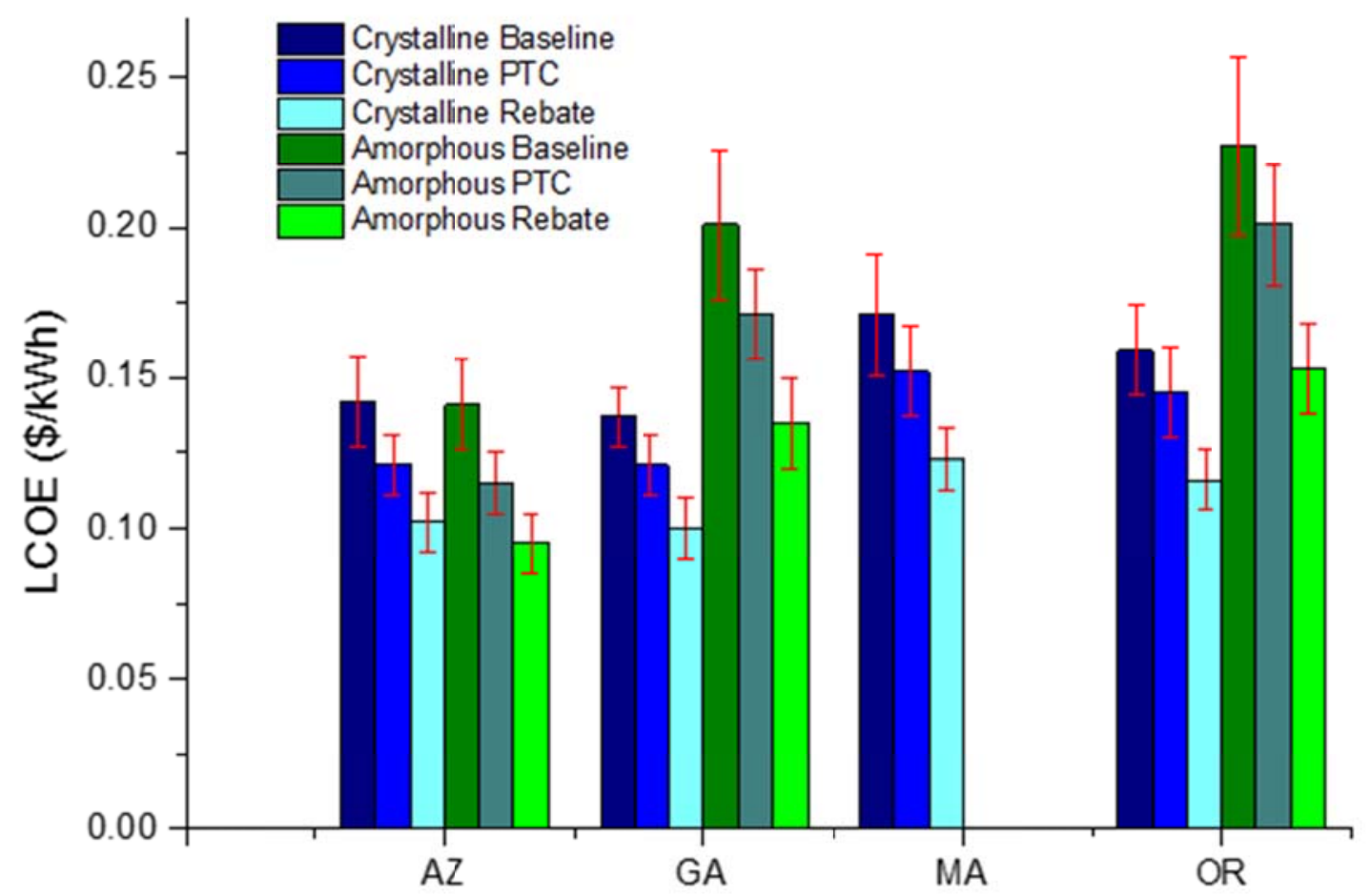

Figure 5: Impact of two policy tools, production tax credits (PTC) and rebates, on LCOE for each region and technology. 